Iran Journal of Nursing (IJN)

Vol 34, No. 132, Oct 2021: 77- 88

\title{
Effects of Infant Massage on Depressed Mood in Mothers of Preterm
}

\section{Infants}

\author{
Maryam Keshavarz $^{1}$, Ali Montazeri ${ }^{2}$
}

\begin{abstract}
Background \& Aims: According to statistics, about $10 \%$ to $12 \%$ of babies born in developing countries are preterm. Iran is among the countries with a high incidence of preterm birth. Some babies require care in a neonatal intensive care unit (NICU). Premature birth is an emotional crisis for parents, and the hospitalization of preterm infants in the NICU is a cause of many families' suffering. Mothers of preterm infants experience emotional shock and may express feelings such as a depressed mood.

Approximately, 28 to $70 \%$ of the mothers of preterm infants experience significant degrees of stress. Parents of preterm infants often suffer much psychological distress due to enduring the infant's unknown clinical conditions in the NICU, observation of aggressive treatments, and not participating in infant care. Therefore, it is essential to pay attention to the mental health of mothers of preterm infants. Previous studies have revealed limited information on the mood and mental state of mothers of preterm infants. Most studies have examined the effects of massage on the physical and psychological state of preterm infants, but few studies have investigated the effect of massage on their mothers' moods. The purpose of this study was to investigate the impact of infant massage on depressed mood of mothers of preterm infants who were discharged from the NICU.

Materials \& Methods: In this quasi-experimental clinical trial which was conducted during October 2015-April 2016, 70 mothers and their preterm infants with fetal age of 32-37 weeks were assigned to one experimental and one control group. The study population was primiparous Iranian women whose preterm infants were hospitalized in the NICU for at least two days and were supposed to be discharged from the ward within the next 24 hours. A continuous sampling method was used so that on consecutive days in the morning shift, research samples were selected from eligible mothers and infants. After studying the infants' records and visiting a specialist, eligible mothers whose infants were ordered to be discharged within the next 24 hours were included in the study. The following cases were removed from the study: mothers who were not willing to continue participating in the study, early discharge of the infant with the personal consent of the parents, and the need to extend the infant's hospitalization days. To prevent the exchange of information between mothers, different groups participated in sampling every week. Code 1 or 2 was assigned to each group. Sampling was started by selecting one of the two cards marked with numbers 1 and 2 assigned to each group. Data were collected by a research assistant who was blind to the groups' assignment. In the morning shift, before the day of discharge, the depressed mood of Profile of Mood States Questionnaire (POMS) was completed by the mothers of the two groups. A depressed mood score was obtained in response to 15 questions of the depressed mood of McNair's questionnaire. In the experimental group, the intervention consisted of 8 minutes of massage consisting of two identical standard parts (four minutes each part). The first part was performed by the researcher, and the second part by the mother. To prevent friction, the researcher dripped his fingertips in almond oil and placed the baby in a prone position, and massaged the child with his palms at medium pressure for four one-minute periods. Each minute consisted of 12 movements and each movement took five seconds, from the tip of the head down to the neck and vice versa and from the upper part of the back down to the waist and vice versa. It should be noted that the two movements were performed once on the right side and once on the left side of the baby's body, and in performing the movement on the baby's back, the baby's spine was not touched at all. The mother then repeated the massage movements performed by the researcher for four minutes. The massage was repeated in two parts on the day of discharge, so that the massage

1. Department of Midwifery and Reproductive Health, Nursing Care Research Center (NCRC), School of Nursing and Midwifery, Iran University of Medical Sciences, Tehran, Iran (Corresponding Author) Tel: 021-43651183 Email: Keshavarz.m@iums.ac.ir

2. Population Health Research Group, Health Metrics Research Centre, Iranian Institute for Health Sciences Research, ACECR, Tehran, Iran
\end{abstract}


was done in the first 4 minutes by the researcher and in the second 4 minutes by the mother. After the intervention, the depressed mood was re-measured. In all stages of massage, in case of infant crying, urination, or defecation, tactile stimuli were stopped and then intervention continued. The control group received no intervention.

Results: Out of 75 mother-infant dyad participating in the study, 70 completed the study. 5 cases withdrew from the study (three and two mother-infant dyad in the experimental and control groups, respectively). Three samples were excluded from the study due to readmission (two in the experimental group and one in the control group) and two samples were removed from the study due to discharge with the personal consent of the parents (one in each group). Out of 70 mother-infant dyad, 35 remained in each group. There was no significant difference between the two groups in terms of demographic characteristics. On the day of discharge, there was a significant difference in the mean scores of depressed mood between the experimental and control group (6.37 \pm 3.54 and $9.34 \pm 5.27, \mathrm{p}=0 / 007$, respectively). In addition, on the day of discharge, the mean of depressed mood significantly decreased in the two groups $(\mathrm{p}=0 / 001)$.

Conclusion: The results showed that observing the infant massage and then performing this massage by the mother twice (once the day before discharge and once on the day of infant discharge) reduced the mean scores of their depressed mood compared to mothers in the control group. However, the mean score of depressed mood in both groups on the day of discharge significantly decreased compared to the previous day, which could be due to reduced anxiety of mothers in both groups when discharging their babies. Hospitalization in the neonatal intensive care unit increases parental concern, anxiety, and depression. The use of simple, inexpensive, and accessible methods, including tactile communication between mother and baby, will positively affect mothers' moods and mental states while creating numerous benefits for the baby. Undoubtedly, the mother's continuation of baby massage in the family environment as the development of healthy habits, way of thinking, and belief in improving these mothers' mental conditions under complex mental states is of great importance. Researches on maternal postpartum behaviors are related to the oxytocin and the placental corticotrophin-releasing hormone. One of the mechanisms of the effect of infant massage on the mother is its effect on the oxytocin. Oxytocin plays a crucial role in developing behaviors related to interpersonal relationships, including the emotional relationship between mother, infant, and child. Therefore, the mechanism of oxytocin action in the central nervous system and the occurrence of certain behaviors due to its effect has recently been considered by psychiatrists. Undoubtedly, identifying the mothers of infants with a depressed mood and providing support for these mothers will significantly reduce the incidence of postpartum depression. Training mothers on how to perform massage has an essential role in the mother's mental health and reduces the mother's mood disorders. Community-based health care must be at the forefront of care planning.

Keywords: Infant massage, Preterm infants, Mothers' depressed mood

\section{Conflict of Interest: No}

How to Cite: Keshavarz M, Montazeri A. Effects of Infant Massage on Depressed Mood in Mothers of Preterm Infants. Iran Journal of Nursing. 2021; 34(132):77-88.

Received: 17 Jul 2021

Accepted: 16 Oct 2021 


\title{
تأثير ماساز نوزاد بر خلق افسرده مادران نوزادان نارس
}

\author{
مريم كثاورز '، على منتظرى
}

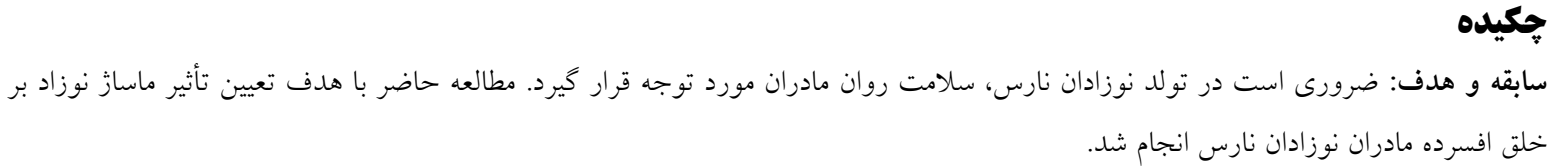

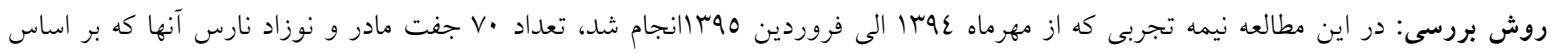

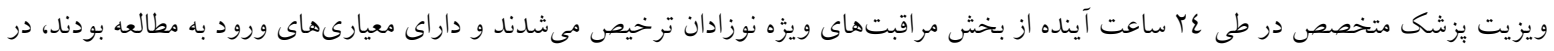

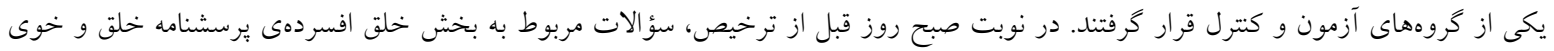

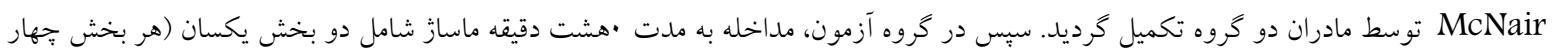

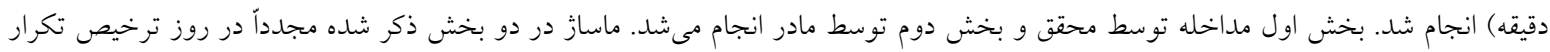

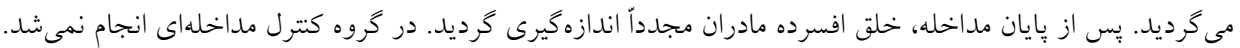

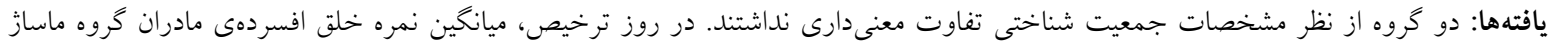

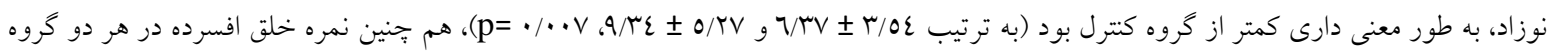

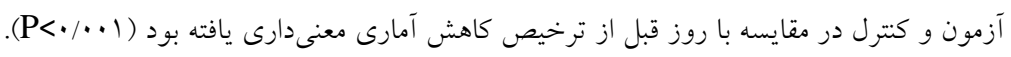

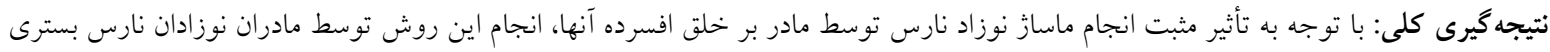

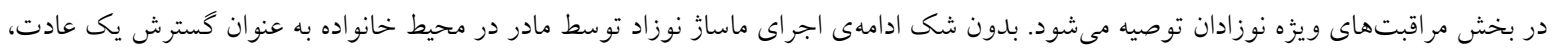

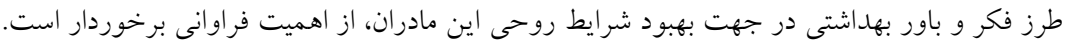
كليد وازهها: ماساز نوزاد، خلق افسرده مادران. تعارض منافع: ندارد

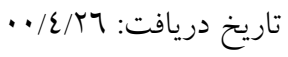

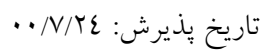

'. كروه مامايى و بهداشت بارورى، مركز تحقيقات مراقبتهاى يرستارى، دانشكده برستارى و مامايى، دانشكاه علوم بز شكى ايران، تهران، ايران.

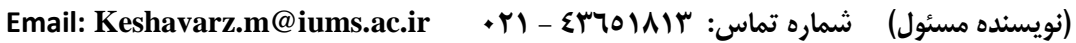

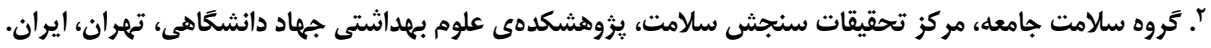


از تأثير ماساز بر نوزادان(17-1)، هم جنين فوايد تأثير ماساز

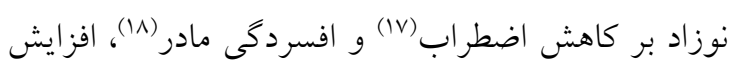

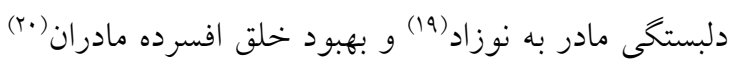
ارائه شده است. در يك مطالعه در مقايسهى انجام ماساز توسط مادر با مشاهده ماساز در مادرانى كه نوزاد نارسشان

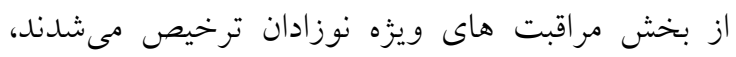

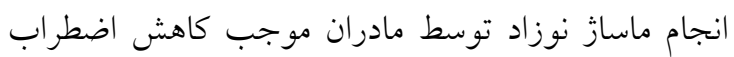

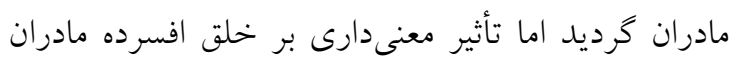

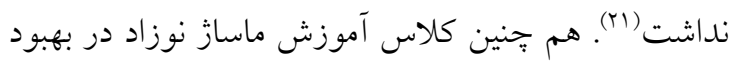
تعامل مادر با كودى مؤثر بوده است، ولى از نظر نمره

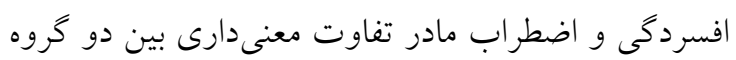

آموزش ماساز نوزاد و كروه كنترل مشاهده نشد (rr).

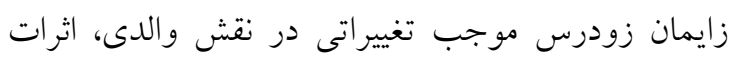

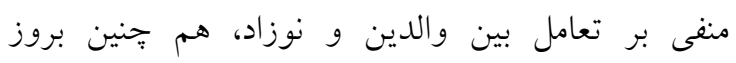

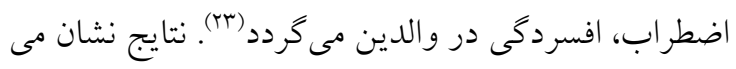
دهد كه بهبود تعامل بين مادر و نوزاد نقش مؤثرى درد درد

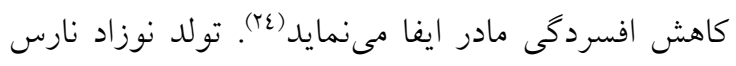

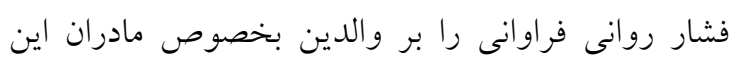

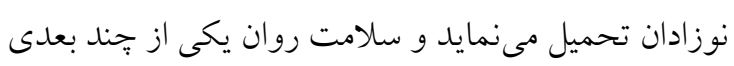

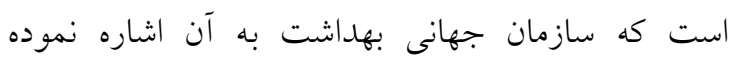

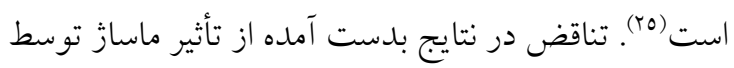
مادر بر خلق مادران بر ضرورت انجام اين مطالعه مى افزايد.

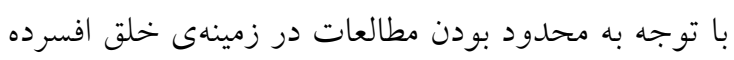

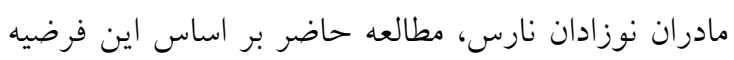

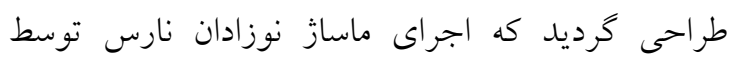
مادرانشان، موجب بهبود خلق افسرده آنان مى كردد.

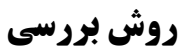

اين مطالعه نيمه تجربى بال شماره كارآزمايى 326/130 IRCT201305262324N10 ثبت كرديده است. مطالعه با دو گروه ماساز نوزاد و كتترل

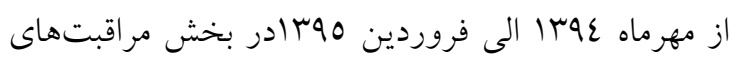

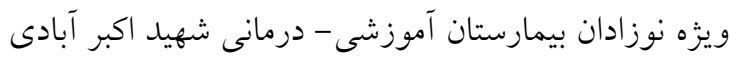

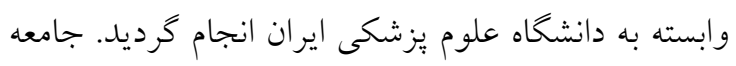

\section{مقدمه}

سالانه حدوداً $ه ا$ ميليون نوزاد نارس در سراسر جهان متولد مىشوند. اين آمار رو به افزايش، تقريباً 17 درصد كل

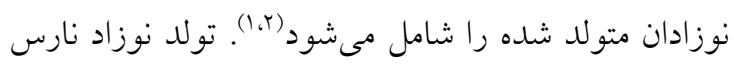

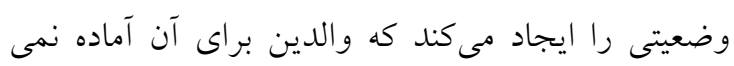

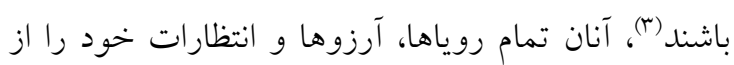
دست رفته مى بندارند و اين رويداد غير منتظره، اضطراب

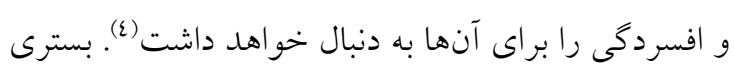
شدن نوزادان نارس در بخش مراقبتهاى ويزٔى نوزادان،

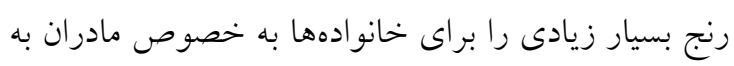

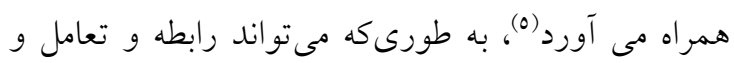
دلبستخى بين مادر و نوزاد را تحت تأثير خود قرار دهد (7). اين مادران براى داشتن نوزاد نارس آمادگى لازم را ندارند و ميزان بالاترى از احساسات منفى جون استرس، اضطراب و افسردگى را تجربه مئنمايند (V^). والدين نوزادان نارس به علت تحمل شرايط بالينى نا معلوم نوزاد در بخش مراقبتهاى ويزه نوزادان، مشاهده درمان هاى تهاجمى و عدم مشاركت در مراقبتهاى نوزاد، مكرراً رنج روحى زيادى را متحمل مىشوند (9). نتايج مطالعات مختلف نشان مىدهد كه والدين نوزادان نارس بسترى به

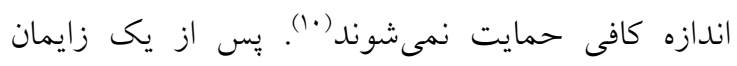

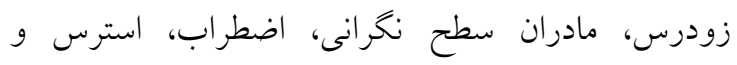
افسردگى بالاترى نسبت به يدران تجربه مى كنند و آمار

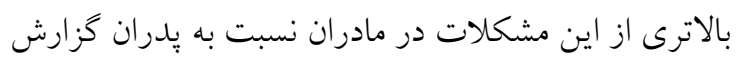
شده است(0)، بروز اين مشكلات در اين مادران مىتواند موجب اختلال در تعامل و ارتباط عاطفى مادر و نوزاد، اختلال در خواب و توانايى برقرارى ارتباط مادر با ديخر اعضاى خانو اده مى كردد (11). لمس اولين سيستم حسى است كه تكامل مىيابد و مبناى تعاملات ميان شيرخوار و والدين است، بنابراين ماساز درمانى يكى از مهمترين روشهاى تبادل عاطفى براى والدين و شير خواران محسوب مى كردد(ז'). در طى دهـ هاى اخير، ماساز درمانى در طى دوره نوزادى به عنوان

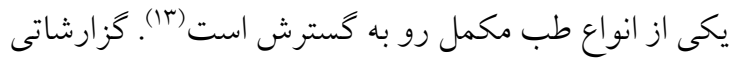


يرونده يزشكى نوزاد و اطلاعات مادر با يرسش از وى

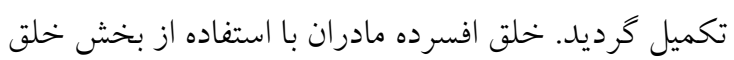

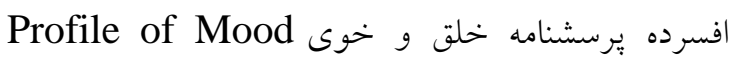
تعيين گرديد. اين برسشنامه توسط States (POMS)

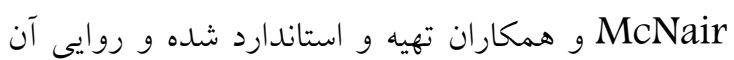

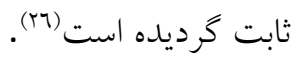
اين يرسشنامه احساسات و حالتهاى خلقى را توصيف مى كند و به عنوان يك ابزار تحقيقاتى در تشخيص تغييرات حالات عاطفى در افراد سالم از نظر روانى مورد استفاده

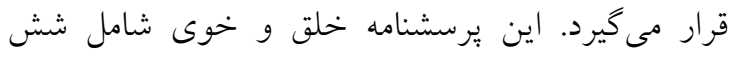
حالت روانى يا عاطفى: تنش و اضطراب (9 كويه)، افسردگى (10 گويه)، خشم و خصومت (11 كويه)،

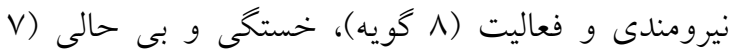
كويه)، سردرگمى و اغتشاش فكرى (V گويه) است كه مجموعه سؤالات مختص به يك عامل خلق با يكديكر

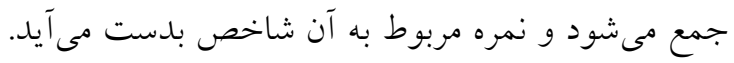

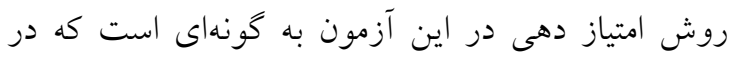

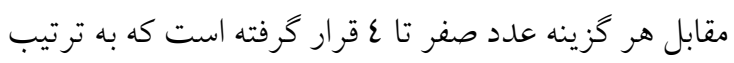
به معناى به هيج وجه، كم، متوسط، تقريباً زياد و خيلى زياد

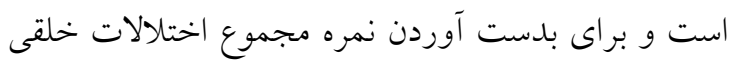

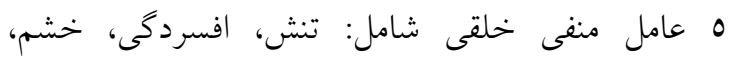

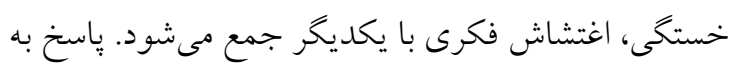

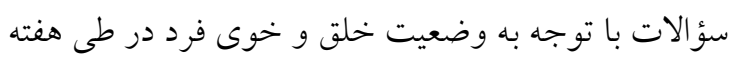

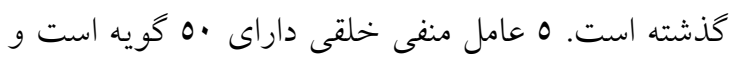

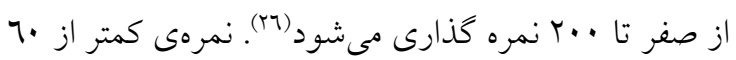

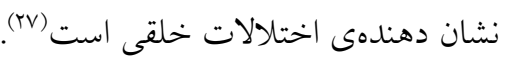
در اين مطالعه فقط از بخش خلق افسرده يرسشنامه خلق و خوى استفاده شد. نمره خلق افسرده از مجموع امتيازهاى

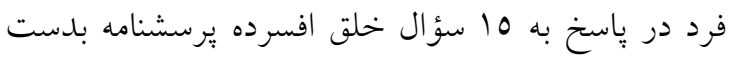

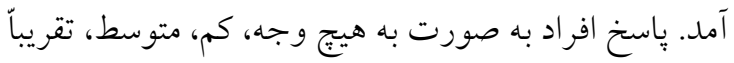
زياد و خيلى زياد بود كه به ترتيب با توجه به مقياس ليكرت از نمره · تا ع در نظر كرفته شد. طيف نمره اين

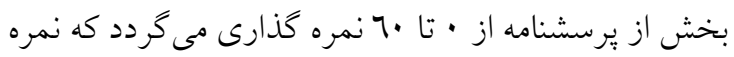

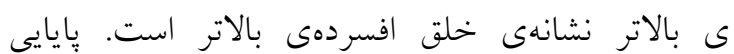

يزّوهش مادران نخستزاى ايرانى بودند كه نوزادان نارس

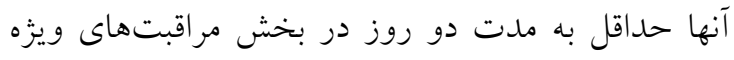

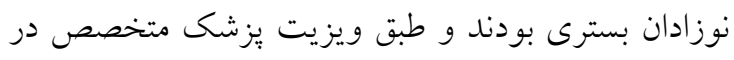

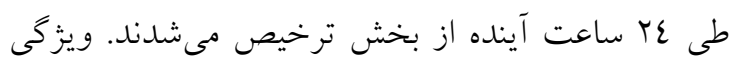

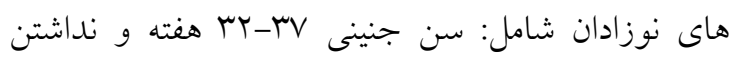

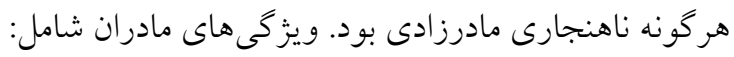
سن •ع-1/ سال، باردارى تك قلويى و بدون عارضه،

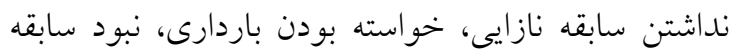

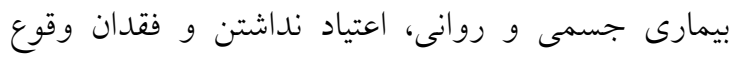
حوادث ناكوار طى سه ماه گذشته (طبق اظهار شركت كننده) بود. در صورت تمايل نداشتن مادر به ادامه شركت

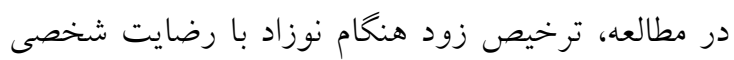
و الدين و نياز به تمديد روزهاى بسترى نوزاد، نمونههاى يزّوهش از مطالعه خارج مىشدند.

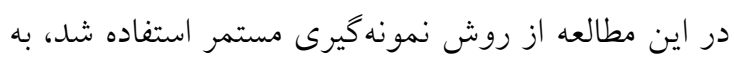
طورى كه در روزهاى متو الى در شيفت صبح از ميان مادران

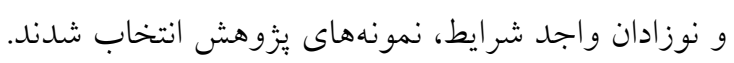

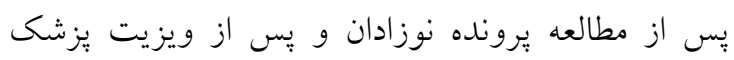

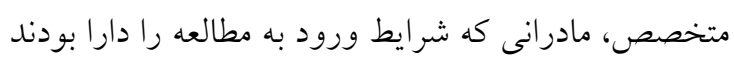

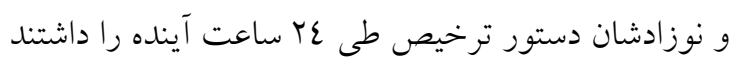

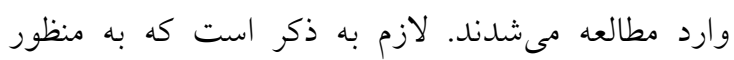

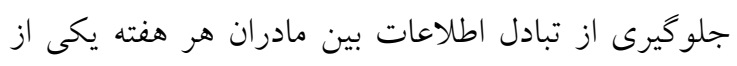

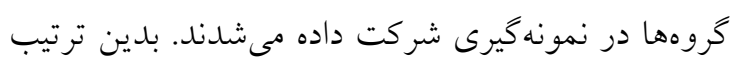

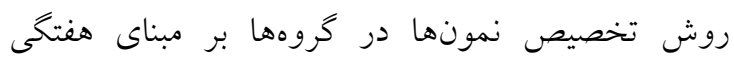

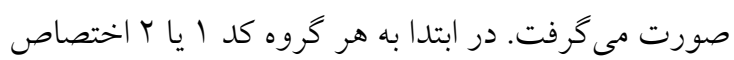

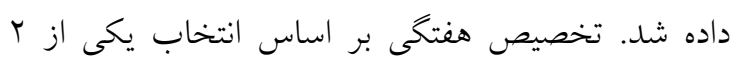

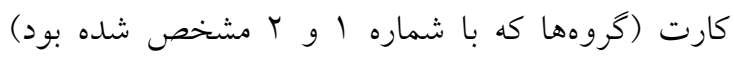
توسط يكى از كاركنان كه از اهداف مطالعه آكاهى نداشتند إنداه

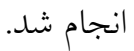
ابزار جمع آورى اطلاعات يُرسشنامه دموكرافيك شامل متغيرهاى سن، سطح تحصيلات و اشتغال مادر، تعداد باردارى و سقط، نوع زايمان، سطح تحصيلات و وضعيت ستيك

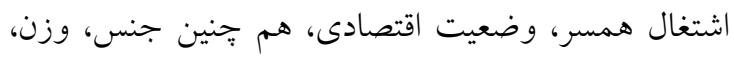

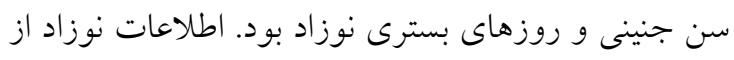


انجام مىشد. در روز اول ابتدا مادر در يك محيط آرام قرار

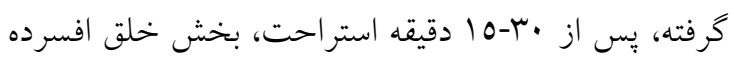

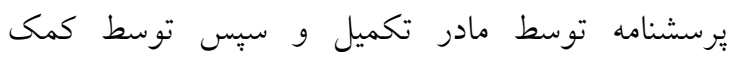

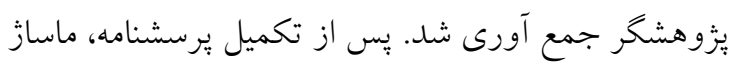

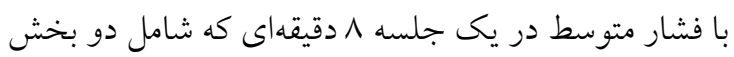
يكسان ع دقيقهاى بود اجرا مىشد. در ع دقيقه اول ماساز توسط محقق انجام مى گرفت و مادر به مشاهده ماساز

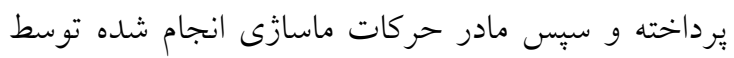

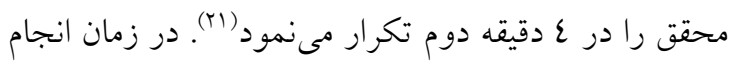

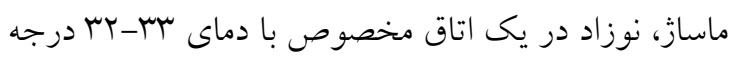
سانتيكر اد قرار خرفته و از لباس مخصوص ماساز (كه علاوه بر حفظ دماى بدن نوزاد، انجام ماساز بر بدن عريان نوزاد

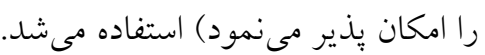

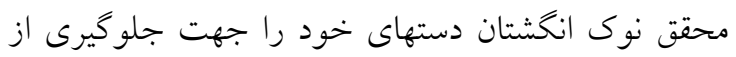

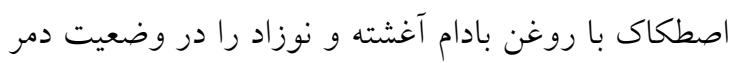
قرار مىداد و با استفاده از كف انخشتان دست و با فشار متوسط به صورت ع دوره يك دقيقهاى كه هر دقيقه آن شامل rا حركت و هر حركت به مدت 0 ثانيه بود انجام

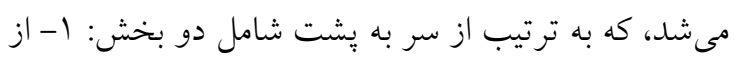

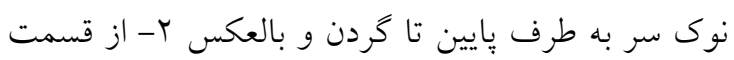

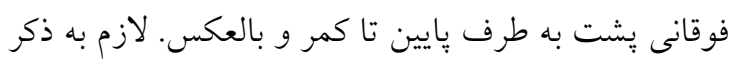

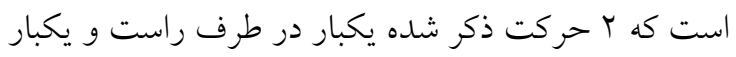

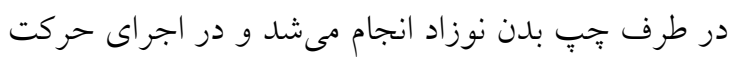

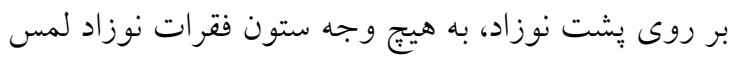
نمى شد. سيس مادر به مدت ع دقيقه حركات ماسازى انجام

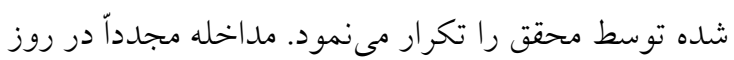
ترخيص به شكل ذكر شده انجام مى گرديد، به طورىكه

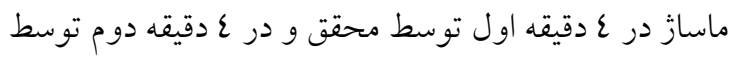
مادر انجام مىشد. لازم به ذكر است كه در كل مراحل انجام

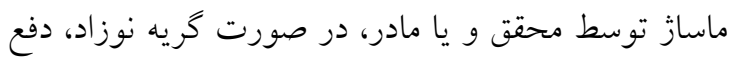

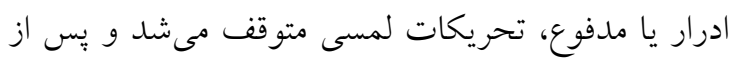

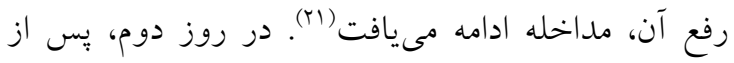

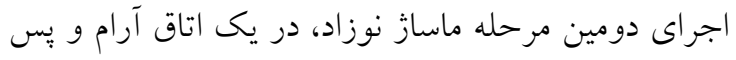

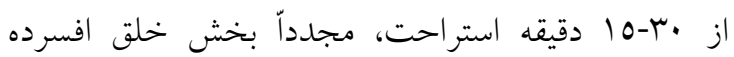

يرسشنامه خلق افسرده توسط شفيع زاده در ورزشكاران

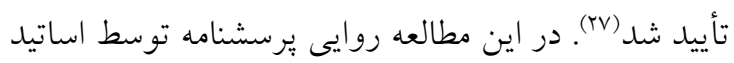
محترم دانشكده يرستارى و مامايى ايران مورد تأييد قرار

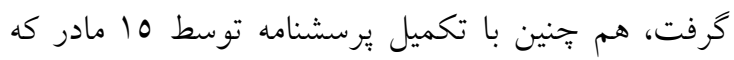

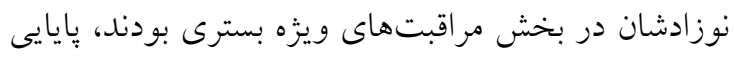

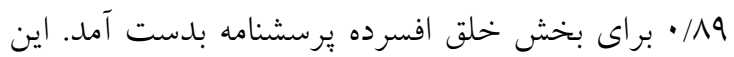

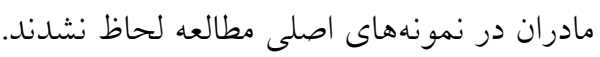

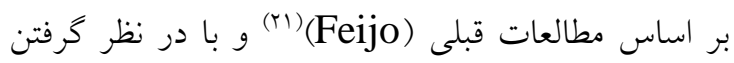

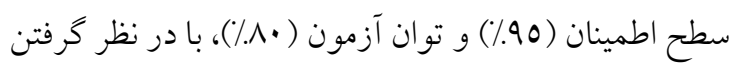

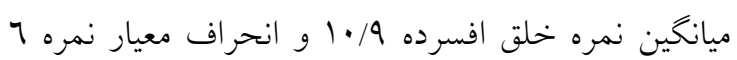

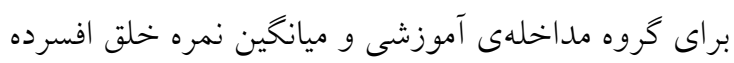

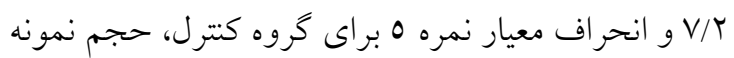

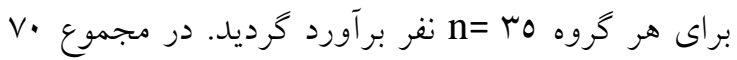
مادر تا انتهاى مطالعه در اين يُزوهش شركت نمودند.

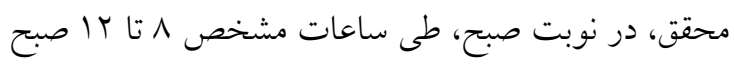

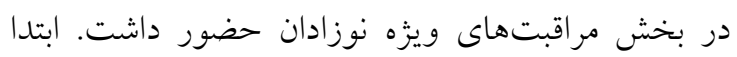
اطلاعات فردى نوزادانى كه شرايط ورود به مطالعه را دارا

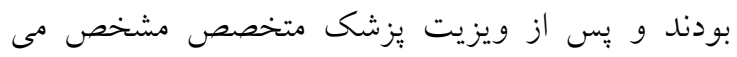

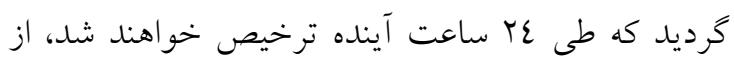

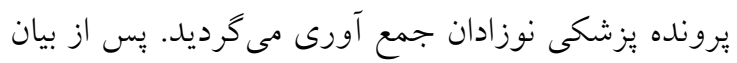

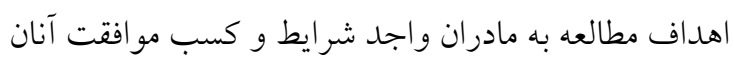

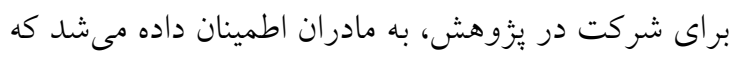

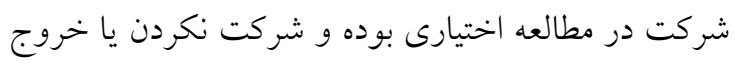

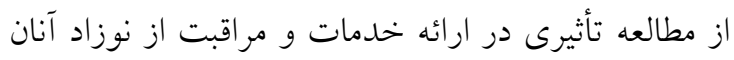

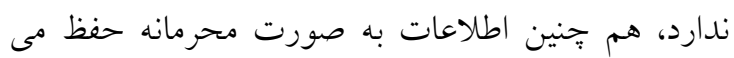

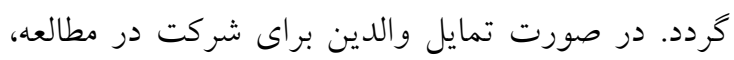

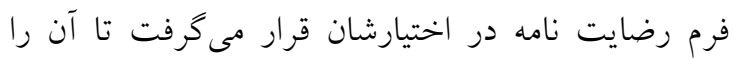

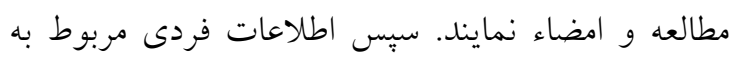

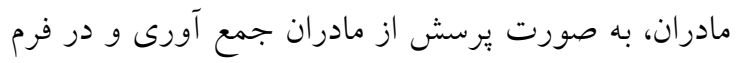
دادهها ثبت مى گرديد. جهت جلو گيرى از ارتباط مادران، نمونههاى مطالعه به صورت يكى هفته در ميان در يكى از دو گروه، مداخلهى ماساز و كنترل قرار مى گرفتند.

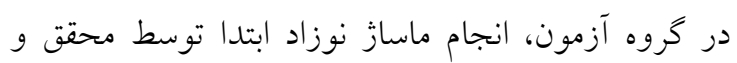

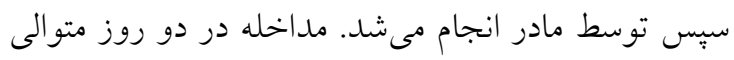




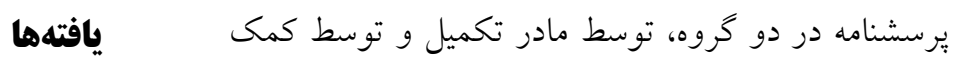
مطالعه حاضر از نوع نيمه تجربى بود. از لم Vم نمونه شركت يُوهشخر جمع آورى مى گرديد. در كروه كنترل هيج

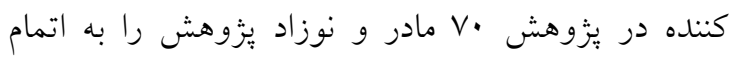

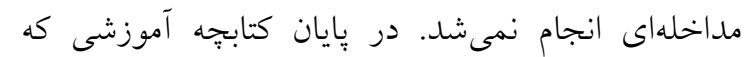

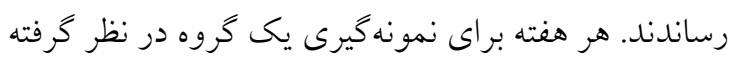

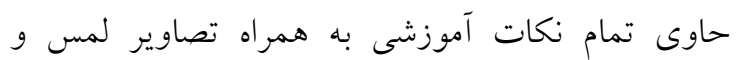

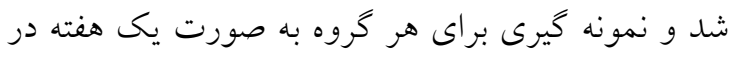

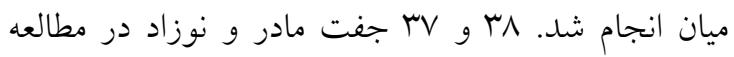
شركت داده شدند كه در نهايت تعداد مب نمونه در هر كروه

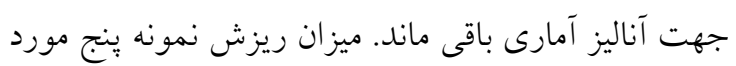

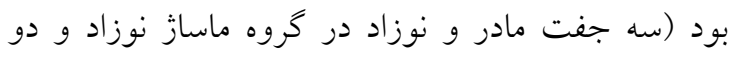

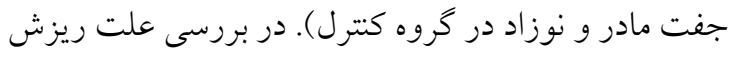
نمونه، سه نوزاد به علت بسترى مجلدد (دو نوزاد در كروه

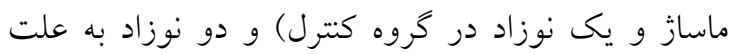
ترخيص با رضايت شخصى والدين از يُزوهش حذف فرس شدند (يك نوزاد در هر يك از گروههاى ماساز و كنترل)

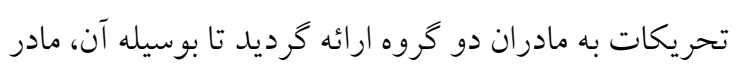
بتواند ماساز را در منزل نيز ادامه دهد.

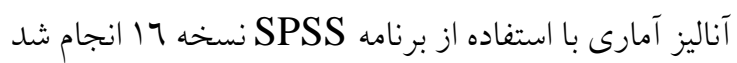
و از آزمون كولموخراف اسميرنوف Kolmogorov جهت بررسى نرمال بودن متغيرهاى Smirnov test) كمى استفاده شد. در موارد نرمال نبودن متغيرها، از آزمون

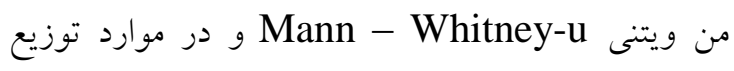
نرمال از آزمون آمارى تى مستقل Independent T Test جهت مقايسه ميانكين متغيرها بين دو گروه استفاده شد.

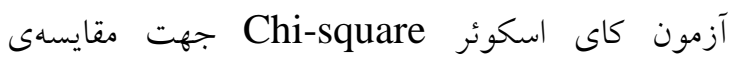
متغيرهاى كيفى و آزمون تى زوجى Paired T Test براى

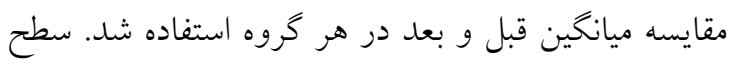
معنى دارى 0 ×• در نظر كرفته شد.

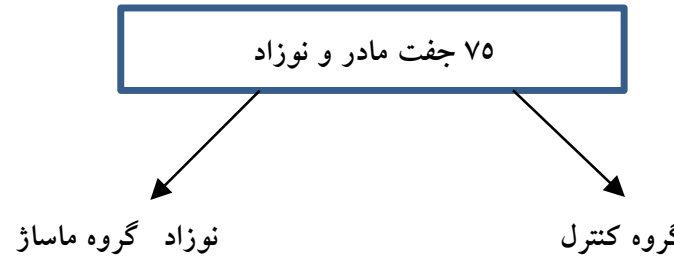

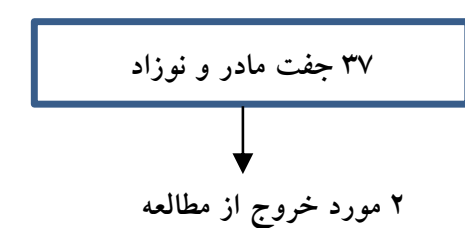

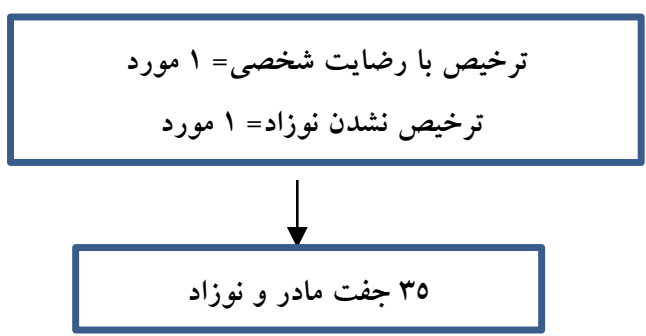

نمودار شماره ا: نمودار كانسورت انتخاب، ورود و موارد خروج شركت كنندًان در مطالعه 
مادران ارايه مى گردد. نتايج نشان داد كه دو گروه از نظر

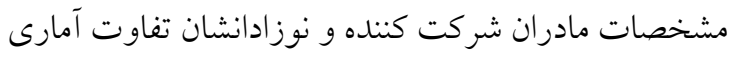
معنى دارى نداشتند (جدول شماره ()).
نتايج ارايه شده، بخشى از نتايج مطالعه با عنوان بررسى

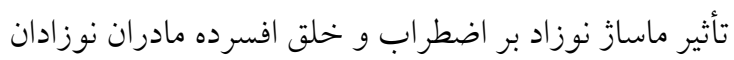
بسترى در بخش مراقبتهاى ويزه نوزادان بود كه در اين

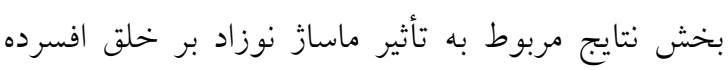

جدول شماره (: مشخصات دموَّر افيك مادران و نوز ادان در دو تروه ماساز نوزاد و كنترل

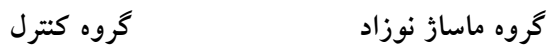

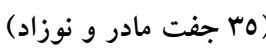

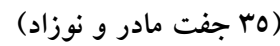

\begin{tabular}{|c|c|c|c|c|}
\hline \multirow[t]{4}{*}{$\mathrm{P}=* \cdot / 7 \cdot V$} & $\operatorname{IV}(\varepsilon \wedge / 0 \wedge)$ & $1 \varepsilon(\varepsilon \cdot)$ & $19-Y \varepsilon$ & \\
\hline & $I r(r \varepsilon / T q)$ & $1 \cdot(Y \wedge / 7 Y)$ & 10-r. & سن مادر (سال) \\
\hline & $\varepsilon(11 / \varepsilon 7)$ & $\wedge(Y Y / V \varepsilon)$ & mo & تعداد (درصد) \\
\hline & $r(0 / 7 V)$ & $r(\Lambda / \neg \varepsilon)$ & ra-rq & \\
\hline \multirow[t]{2}{*}{$\mathrm{P}=* \cdot / \pi V r$} & $\mu(q \varepsilon / T V)$ & M $(\Lambda \Lambda / \neg \varepsilon)$ & خانهدار & وضعيت شغلى \\
\hline & $r\left(O N{ }^{r}\right)$ & $\varepsilon(11 / r 7)$ & شاغل & \\
\hline $\mathrm{P}=* * \cdot \mu q 4$ & $11(\Gamma / / 27)$ & $\wedge(Y Y / q \varepsilon)$ & خوب & \\
\hline$\chi^{2=\cdot / \varepsilon V T}$ & $r Y(T r / M \Lambda)$ & $19(0 \varepsilon / 1 Y)$ & متوسط & وضعيت اقتصادى \\
\hline $\mathrm{df}=\mathrm{r}$ & $r(0 / 77)$ & $\wedge(Y Y / q \varepsilon)$ & ضعيف & \\
\hline \multirow[t]{2}{*}{$\mathrm{P}=* \cdot / 071$} & $T(I V / T \varepsilon)$ & $9(T O / N T)$ & اسقط & تاريخجه سقط \\
\hline & $1(Y / M \Lambda)$ & $\cdot(\cdot)$ & 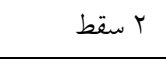 & \\
\hline $\mathrm{P}=* * \cdot /$ TrO & $\operatorname{IV}(\varepsilon \wedge / O \wedge)$ & $\mathbb{I}(r \varepsilon / r \varepsilon)$ & طبيعى & نوع زايمان \\
\hline $\begin{array}{c}\chi^{2}=\cdot / \Sigma V Y \\
\mathrm{df}=1\end{array}$ & $1 \wedge(01 / 2 Y)$ & $r \mu(70 / 77)$ & سزارين & \\
\hline $\mathrm{P}=* * \cdot / \varepsilon \varepsilon$ & $r Y(T r / A V)$ & $r\rceil(V \varepsilon / Y\urcorner)$ & Tr-rE & سن باردارى \\
\hline $\begin{array}{c}\chi^{2=\cdot / \cdot 7} \\
\mathrm{df}=1\end{array}$ & $\mathbb{I r}(\boldsymbol{T V} / \mathrm{T})$ & $q(Y \circ / V \varepsilon)$ & ro-rv & (هفته) \\
\hline \multirow[t]{4}{*}{$\mathrm{P}=* \cdot /$ or. } & $r(\Lambda / \neg r)$ & $r(\Lambda / \neg \mu)$ & $10 \cdots>$ & \\
\hline & $19(0 \varepsilon / \pi)$ & $r \varepsilon(T / O \Lambda)$ & $10 \cdots-1999$ & وزن ن وز وزاد \\
\hline & $\mathbb{I r}(r \varepsilon / \Gamma r)$ & $\Lambda(Y Y / V q)$ & $r \cdots-r \varepsilon 99$ & 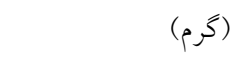 \\
\hline & $1\left(Y / N{ }^{\mu}\right)$ & $\cdot(\cdot)$ & ro.. $<$ & \\
\hline $\mathrm{P}=* * \cdot / \varepsilon r V$ & $\operatorname{IV}(\varepsilon \wedge / O V)$ & $r \cdot(O V / I \varepsilon)$ & دختر & جنس نوزاد \\
\hline $\begin{array}{c}\chi^{2}=\cdot / \varepsilon V Y \\
\mathrm{df}=1\end{array}$ & $1 \wedge(01 / \varepsilon r)$ & $10(\varepsilon Y / \Lambda T)$ & يسر & \\
\hline $\mathrm{P}=* * \cdot / 091$ & $\operatorname{IV}(\varepsilon \wedge / 0 \varepsilon)$ & $\operatorname{IV}(\varepsilon \wedge / 0 \varepsilon)$ & $r-V$ & مدت بسترى نوزاد \\
\hline$\chi^{2}=1 / \cdot r$ & $\mathbb{I r}(r \varepsilon / \Gamma r)$ & $Q\left(Y O / N T^{\top}\right)$ & $\Lambda-1 \mu$ & (روز) تعداد (درصد) \\
\hline$d f=r$ & $7(\mid V / / \varepsilon)$ & $q(T \circ / V T)$ & $1 \varepsilon<$ & \\
\hline
\end{tabular}


نشان مى دهد كه در روز ترخيص ميانخين نمره خلق افسرده

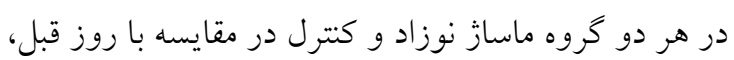
كاهش آمارى معنى دارى داشت. در كروه ماساز ميانخين نمره خلق افسرده از

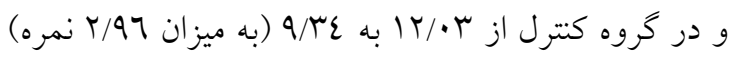

كاهش يافت كه اين كاهش در خروه ماساز بيشتر بود.
ميانخين سن مادران در دو كروه آزمون و كنترل تفاوت آمارى معنى دارى نداشت (r/N r از مداخله ميانخين نمره خلق افسرده در مادران كروه ماساز

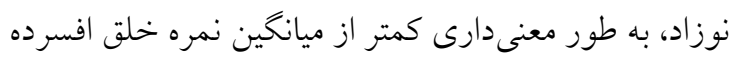

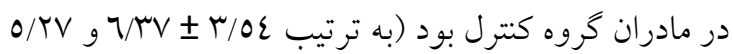

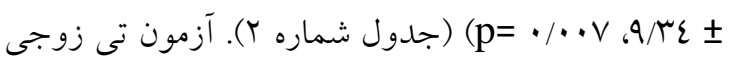

جدول شماره ז: مقايسه نمره خلق افسرده مادران در دو تَروه ماساز نوزاد و كنترل

\begin{tabular}{|c|c|c|c|}
\hline ن نتايج آمارى & كروه كنترل & كروه ماساز نوزاد & \\
\hline $\mathrm{P}=\cdot / \cdot \wedge \varepsilon \quad \mathrm{df}=\urcorner \mathrm{n}=1 / \mathrm{V}^{\prime}$ & $\mid r / \cdot r \pm 7 / 70$ & $|r / 19 \pm 0 / \wedge|$ & ق ق قبل از مداخله \\
\hline \multirow[t]{2}{*}{$\mathrm{P}=\cdot / \cdot V \quad \mathrm{df}=\urcorner \mathrm{u} \quad \mathrm{t}=-r / \mathrm{r}\urcorner$} & $9 / \Gamma \varepsilon \pm 0 / r V$ & $T / T V \pm r / 0 \varepsilon$ & بعد از مداخله \\
\hline & $\mathrm{P}<\cdots / \quad \mathrm{df}=r \varepsilon \quad \mathrm{t}=0 / 0 \wedge$ & $\mathrm{P}<\cdots \cdot \cdots) \quad \mathrm{df}=r \varepsilon \quad \mathrm{t}=1 r / \mu q$ & نتايج آمارى \$ \\
\hline
\end{tabular}

تحقيقات در زمينهى تأثير ماساز نوزاد بر خلق افسرده مادران محدود مىباشد. در مطالعهى Feijo در آمريكا دو مداخلهى مشاهده ماساز و انجام ماساز توسط مادر بر خلق افسرده مادران مقايسه شد. در اين مطالعه خلق افسرده مادران در هر دو كروه كاهش معنىدارى داشت، هر جند مقايسه خلق افسرده مادران بين دو گروه تفاوت معنىدارى نداشت. در مطالعه Feijo، دو گروه مشاهده ماساز و گروه اجراى ماساز مقايسه شدند، هم جنين مداخله در يك نوبت و در روز ترخيص نوزاد نارس از بخش مراقبتهاى ويزه اجرا شد. از نقاط ضعف مطالعهى Feijo را مى توان تعداد كم نمونه (در مجموع ·r مادر در هر گروه) ذكر نمود (YI). در مطالعه Fujita در زاين خلق افسرده مادرانى كه نوزاد خود را به مدت ·ل دقيقه در روز تا ب ماه پس از زايمان ماساز مىدادند بررسى شد. در اين مطالعه ماساز نوزاد

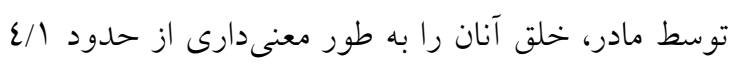

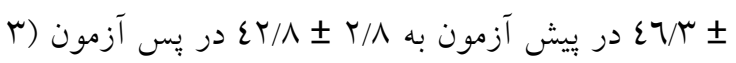
ماه يّ از زايمان) كاهش داد. نتايج نشان داد سه ماه يس از مداخله افسردگى و سطح نيرومندى در گروه آزمون در مقايسه با گروه كتترل بهبود يافته بود، در حالى كه تنش، خشم، خستخى، سردرگمى تفاوت معنى دارى نداشت(بی).
بحث و نتيجه كيرى

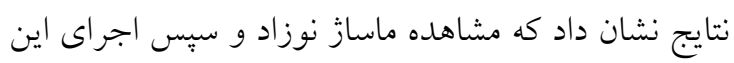
ماساز توسط مادر در دو نوبت (روز قبل از ترخيص و روز ترخيص نوزاد از بخش مراقبت ويزه نوزادان) موجب كاهش خلق افسرده آنان در مقايسه با مادران كروه كنترل شد. هر جّند خلق افسرده در هر دو گروه در روز ترخيص در مقايسه با روز قبل، كاهش معنى دارى داشت كه مىتواند به دليل كاهش نخرانى مادران دو گروه در زمان ترخيص نوزادشان باشد. گزارشاتى از فوايد تأثير ماساز نوزاد بر مادران از جمله

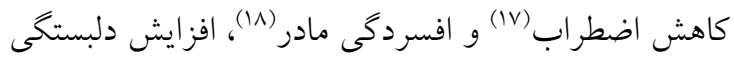

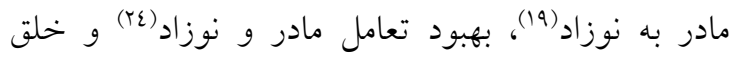
مادران(T9) ارائه شده است. در يكى مطالعه كه در انخلستان با هدف تعيين تأثير ماساز نوزاد بر افسردگى يس از زايمان و تعامل مادر با كودى طراحى شده بود، مشخص شد كه كلاس آموزش ماساز نوزاد در بهبود تعامل مادر با كودى مؤثر بوده است، ولى از نظر افسردگى و اضطراب تفاوت معنى دارى بين دو كروه آموزش ماساز نوزاد و كروه كنترل

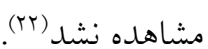


افسرده و ارائه حمايت براى اين مادران در كاهش بروز

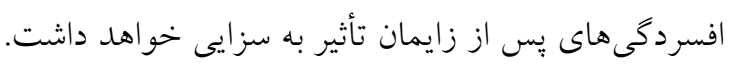

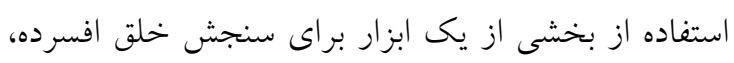

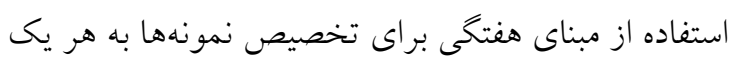

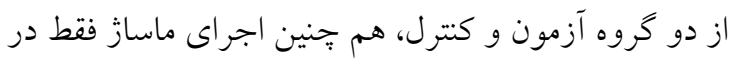
دو روز متوالى از محدوديتهاى اجراى اين مطالعه بود.

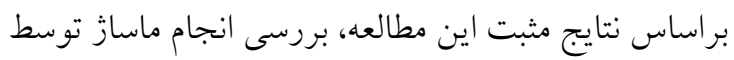

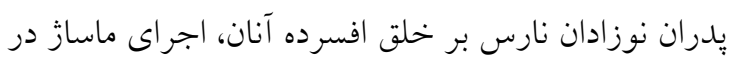

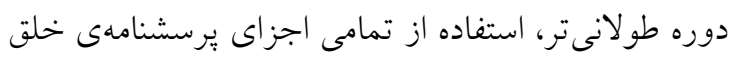

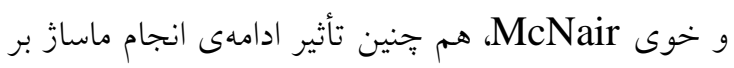

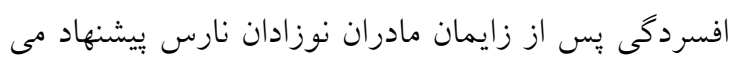

بسترى شدن نوزاد نارس در بخش مراقبتهاى ويزه

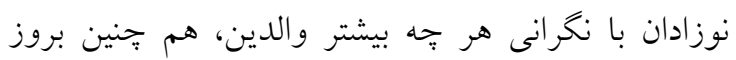

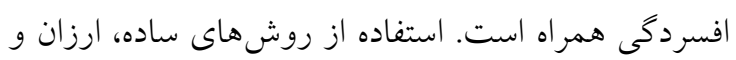

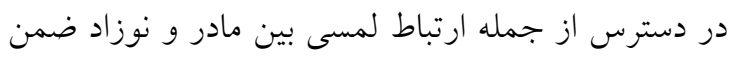

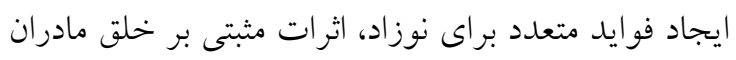

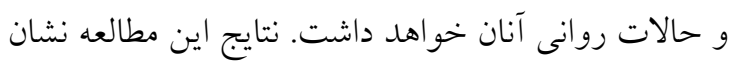

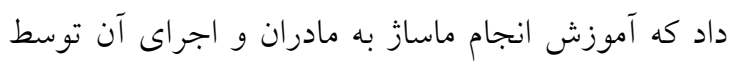
مادر در نوزادان نارس بسترى در بخش مر اقبتهاى ويزه

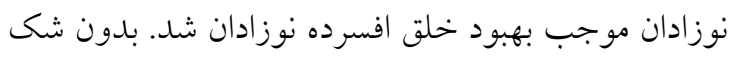

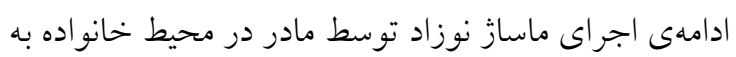

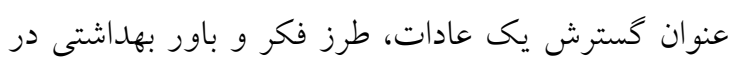

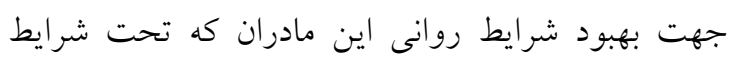

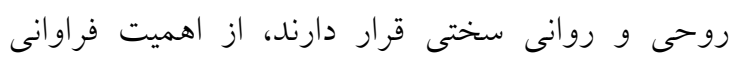
برخوردار است. ضروريست مر اقبتهاى بهداشتى مبتنى بر

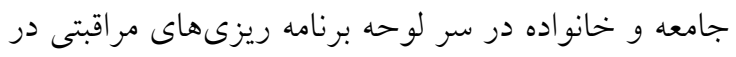

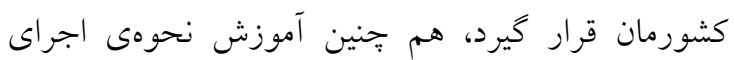
ماساز نوزاد به يرستاران و ماماهاى شاغل در بخشهاى

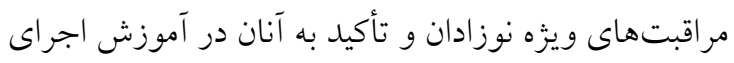
ماساز به مادران و توجه به اجراى روزانه آن توسط مادران مد نظر قرار گيرد. - مانه
در يكى مطالعه كه در كشور جين انجام شد، اجراى بنج روز

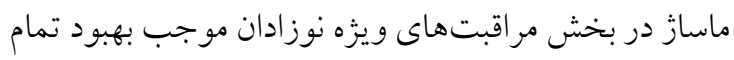
ابعاد خلق مادران نوزادان گروه آزمون گرديد (عَ). شواهدى در زمينه تأثير مثبت ماساز بر كاهش درد و روز هاى بسترى، تكامل عصبى، تحمل بهتر تغذيه و وزن گيرى نئي

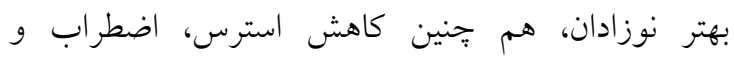

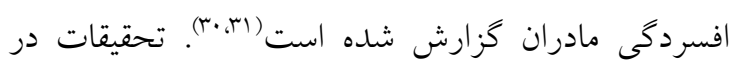

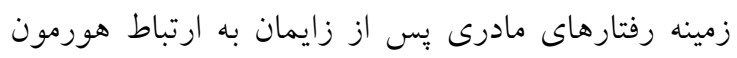

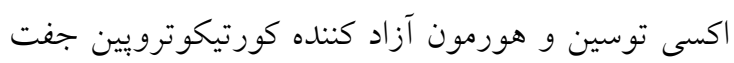

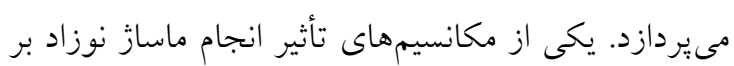

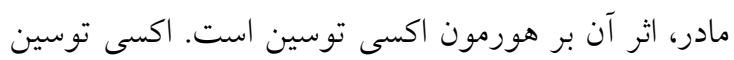

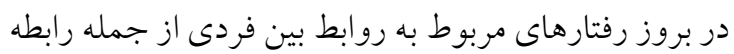

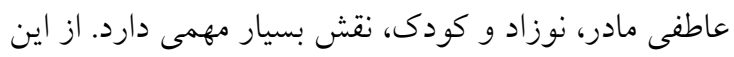
رو مكانيسم عمل اين هورمون در سيستم عصبى مركزى و و وردي

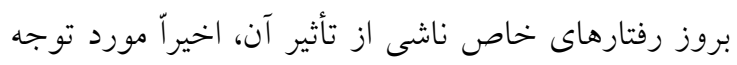

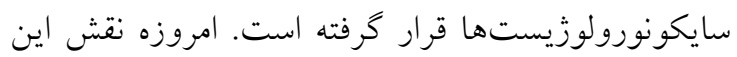
يِتيد در حالات روانى مادر، ميزان عاطفى بودن و زمان

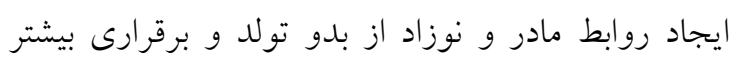
تماس جششمى و يوستى مادر با نوزادش غير قابل انكار

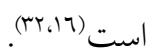

صرف نظر از سن، تحصيلات و وضعيت اقتصادى مادران،

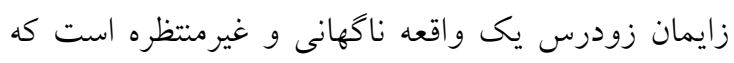

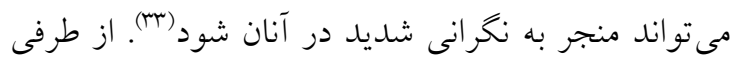

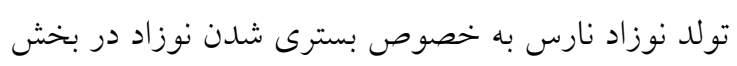

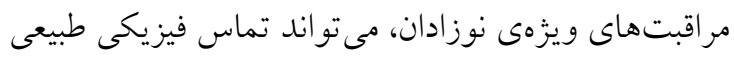

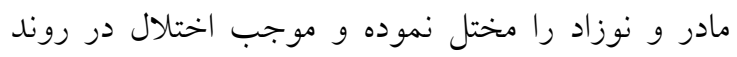

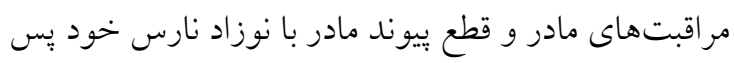

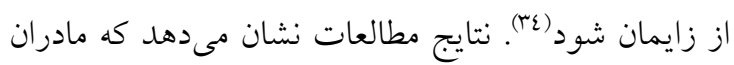

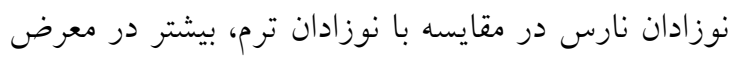

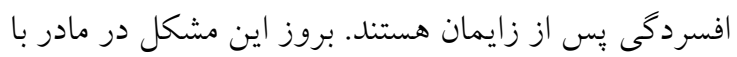

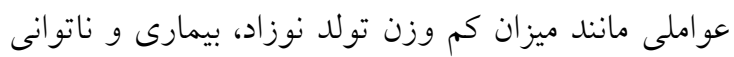

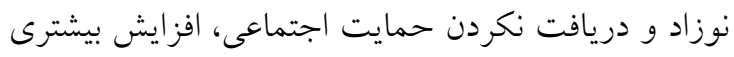

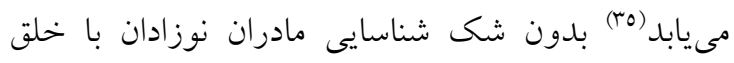




$$
\begin{aligned}
& \text { با يزوهشكر داشتند، هم جنين مادرانى كه در اين طرح }
\end{aligned}
$$

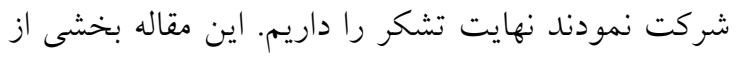

$$
\begin{aligned}
& \text { نتايج پيايان نامه كارشناسى ارشد مامايى (كرايش بهداشت } \\
& \text { مادر و كودى) دانشخاه علوم يزشكى تهران مى باشد. }
\end{aligned}
$$$$
\text { تعارض منافع: نويسندگان اعلام مىنمايند كه تعارض }
$$$$
\text { منافعى در اين مطالعه وجود ندارد. }
$$

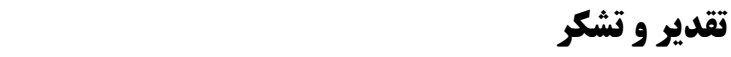

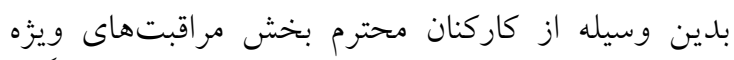

$$
\begin{aligned}
& \text { نوزادان بيمارستان شهيد اكبر آبادى كه نهايت همكارى را }
\end{aligned}
$$

\section{References}

1. World Health Organization. Preterm birth, Available: https://www.who.int/en/news-room/factsheets/detail/preterm-birth [Accessed 28/11 2019].

2. Blencowe H, Cousens S, Oestergaard MZ, Chou D, Moller AB, Narwal R, Adler A, Garcia CV, Rohde S, Say L, Lawn JE. National, regional, and worldwide estimates of preterm birth rates in the year 2010 with time trends since 1990 for selected countries: a systematic analysis and implications. The lancet. 2012;379(9832):2162-72.

3. Arzani A, Valizadeh L, Zamanzadeh V, Mohammadi E. Mothers' strategies in handling the prematurely born infant: a qualitative study. Journal of caring sciences. 2015;4(1):13-24. [Persian]

4. Christiansen DM. Posttraumatic stress disorder in parents following infant death: a systematic review. Clin Psychol Rev. 2017;51:60-74.

5. Alexopoulou P, Evagelou E, Mpakoula-Tzoumaka C, Kyritsi-Koukoulari E. Assessing anxiety and depression in parents of preterm infants. J Neonatal Nurs. 2018;24(5):273-6.

6. Bonacquisti A, Geller PA, Patterson CA. Maternal depression, anxiety, stress, and maternal-infant attachment in the neonatal intensive care unit. J Reprod Infant Psychol. 2020;38(3):297-310.

7. Ong SL, Abdullah KL, Danaee M, Soh KL, Soh KG, Japar S. Stress and anxiety among mothers of premature infants in a Malaysian neonatal intensive care unit. J Reprod Infant Psychol. 2019;37(2):193-205.

8. Ionio C, Mascheroni E, Colombo C, Castoldi F, Lista G. Stress and feelings in mothers and fathers in NICU: Identifying risk factors for early interventions. Primary health care research \& development. 2019;20.

9. Mendizabal-Espinosa RM. A critical realist study of neonatal intensive care in Mexico (Doctoral dissertation, UCL (University College London)). 2017.

10. Mousavi SS, Chaman R, Khosravi A, Mohagheghi P, Mousavi SA, Keramat A. The needs of parents of preterm infants in Iran and a comparison with those in other countries: a systematic review and meta-analysis. Iranian journal of pediatrics. 2016;26(5). [Persian]

11. Granero-Molina J, Medina IM, Fernández-Sola C, Hernández-Padilla JM, Lasserrotte MD, Rodríguez MD. Experiences of mothers of extremely preterm infants after hospital discharge. $J$ Pediat Nurs. 2019;45:e2-8.

12. Wong DL, Hockenberry MJ, Wilson D. Essentials Pediatric Nursing Children. Mosby Elsevier, ST. Louis. 2009:783-94.

13. Chen SC, Yu J, Yuen SC, Lam JC, Suen LK, Yeung WF. Massage therapy in infants and children under 5 years of age: protocol for an overview of systematic reviews. Systematic reviews. 2021;10(1):1-9.

14. Cordeiro AL, de Andrade CL, França FS, Carvalho M, Pinto LM. Effects of therapeutic massage on premature newborn in the neonatal intensive therapy unit: a systematic review. Revista Pesquisa em Fisioterapia. 2019;9(4).

15. Keshavarz M, Babaee Gh, Dieter J. Effect of Tactile-Kinesthetic Stimulation in weight gaining of pre-term infants hospitalized in intensive care unit. Tehran University Medical Journal TUMS Publications. 2009;67(5):347-52. [Persian]

16. Field T. Pediatric massage therapy research: a narrative review. Children. 2019;6(6):78.

17. Afand N, Keshavarz M, Fatemi NS, Montazeri A. Effects of infant massage on state anxiety in mothers of preterm infants prior to hospital discharge. J Clin Nurs. 2017;26(13-14):1887-92. 
18. Dehkordi Z, Hosseini-Baharanchi F, Kazemian A, Madiseh M, Reisi M, Motaghi B. The effects of infant massage on maternal postpartum depression: A randomized controlled trial. Nursing and Midwifery Studies. 2019;8(1):28-33. [Persian]

19. Gürol A, Polat S. The effects of baby massage on attachment between mother and their infants. Asian nursing research. 2012; 6(1):35-41.

20. Lotfalipour B, Tirgari B, Pouraboli B, Mirzaee M. Effect of preterm infant massage by the mother on the mood of mothers having preterm infants. Journal of Chiropractic Medicine. 2019;18(1):6776.

21. Feijó L, Hernandez-Reif M, Field T, Burns W, Valley-Gray S, Simco E. Mothers' depressed mood and anxiety levels are reduced after massaging their preterm infants. Infant Behavior and Development. 2006; 29(3):476-80.

22. Roberts IS, Glover V. Postnatal depression and mother and infant outcomes after infant massage. $J$ Affec Disord. 2008; 109(1-2):189-92.

23. Ionio C, Mascheroni E, Colombo C, Castoldi F, Lista G. Stress and feelings in mothers and fathers in NICU: Identifying risk factors for early interventions. Primary health care research \& development. 2019; 20.

24. Xie J, Zhu L, Zhu T, Jian Y, Ding Y, Zhou M, Feng X. Parental Engagement and Early Interactions With Preterm Infants Reduce Risk of Late Postpartum Depression. J Nerv Mental Disease. 2019;207(5):360-4.

25. Haery SM, Tehrani H, Olyaeimanesh A, Nedjat S. Factors influencing the social health of employees of the ministry of health and medical education in Iran. Iranian Journal of Health Education and Health Promotion. 2016;3(4):311-8. [Persian]

26. McNair DM, Lorr M, Droppleman LF. EdITS Manual for the Profile of Mood States (POMS). Educational and industrial testing service; 1992.

27. Shafi Zadeh A, Zahedi H. The normal profile of mood states in male physical education teachers. Harakat. 2007;32:133-60. [Persian]

28. Fujita M, Endoh Y, Saimon N, Yamaguchi S. Effect of massaging babies on mothers: pilot study on the changes in mood states and salivary cortisol level. Complementary Therapies in Clinical Practice. 2006;12(3):181-5.

29. Hardin JS, Jones NA, Mize KD, Platt M. Affectionate Touch in the Context of Breastfeeding and Maternal Depression Influences Infant Neurodevelopmental and Temperamental Substrates. Neuropsychobiology. 2021;80(2):158-75.

30. Pados BF, McGlothen-Bell K. Benefits of infant massage for infants and parents in the NICU. Nursing for women's health. 2019;23(3):265-71.

31. Field T. Infant massage therapy research review. Clin Res Pediat. 2018;1(2):1-9.

32. Li Q, Becker B, Wernicke J, Chen Y, Zhang Y, Li R, Le J, Kou J, Zhao W, Kendrick KM. Foot massage evokes oxytocin release and activation of orbitofrontal cortex and superior temporal sulcus. Psychoneuroendocrinology. 2019;101:193-203.

33. Ong SL, Abdullah KL, Danaee M, Soh KL, Soh KG, Japar S. Stress and anxiety among mothers of premature infants in a Malaysian neonatal intensive care unit. J Reprod Infant Psychol. 2019;37(2):193-205.

34. Medina IM, Granero-Molina J, Fernández-Sola C, Hernández-Padilla JM, Ávila MC, Rodríguez MD. Bonding in neonatal intensive care units: Experiences of extremely preterm infants' mothers. Women and Birth. 2018;31(4):325-30.

35. Vigod SN, Villegas L, Dennis CL, Ross LE. Prevalence and risk factors for postpartum depression among women with preterm and low-birth-weight infants: a systematic review. BJOG: An International Journal of Obstetrics \& Gynaecology. 2010;117(5):540-50. 